\title{
Comunicação em Saúde: Evitar o Contágio da Doença por Vírus Ébola nos PALOP - Metodologia KISS \& KEYWORDS
}

\author{
Health Communication: Preventing the Spread of Ebola Virus Disease in the \\ Portuguese Spoken African Countries - Methodology KISS \& KEYWORDS
}

\author{
Isabel DE SANTIAGO ${ }^{1,2}$, José Pereira MIGUEL ${ }^{3,4}$, Francisco ANTUNES ${ }^{5,6}$
}

Acta Med Port 2015 Mar-Apr;28(2):141-144

\section{RESUMO}

Neste trabalho, a Comunicação em Saúde é considerada como uma disciplina importante para a Medicina e ciências da saúde pelo seu papel como verdadeiro determinante da saúde. Destaca-se o seu contributo para a promoção da saúde e prevenção da doença. Assim, o Plano de Comunicação em Saúde: Evitar o contágio da doença por vírus Ébola nos Países de Língua Oficial Portuguesa Metodologia KISS \& KEYWORDS é um instrumento que tem por objetivos minimizar o risco de contágio por vírus Ébola nos Países de Língua Oficial Portuguesa e ainda, capacitar para uma melhoria geral das condições sanitárias das populações visadas. No delineamento do Plano de Comunicação em Saúde são, especialmente, considerados os contextos sociais e culturais das populações-alvo, com destaque para os costumes, tradições e religião. A Comunicação em Saúde é encarada como uma Função Essencial da Saúde Pública e nessa medida visa sobretudo a abordagem populacional. $O$ alvo das ações de comunicação são os grupos populacionais em complemento da comunicação individual, os públicos-alvo são populações sem acesso a meios de comunicação, na Guiné Bissau, Cabo-Verde e São Tomé e Príncipe. No âmbito do Plano de comunicação recorre-se a metodologia, modelos e práticas seguidas tanto pelos profissionais da comunicação como da saúde. Numa abordagem de proximidade e de mediação cultural, identificam-se previamente factos-chave, definem-se objetivos, delineia-se o Plano em concreto e sua metodologia de implementação (público-alvo e intervenção a seguir, materiais a utilizar e mensagens-chave, e os parceiros a mobilizar) seguindo as normas da Organização Mundial de Saúde.

Palavras-chave: África; Comunicação em Saúde; Disseminação de Informação; Doença pelo Vírus Ébola; Surtos de Doenças.

\section{ABSTRACT}

In this work, Health Communication is considered as an important discipline in medicine and health sciences for his role as true determinant of health. We highlight their contribution to health promotion and disease prevention. Thus, the Health Communication Plan (PCS): Preventing the spread of Ebola virus disease in the Portuguese Speaking African Countries - KISS \& KEYWORDS methodology is a tool that aims to minimize the risk of infection by Ebola virus in the Portuguese Speaking African Countries and also train for a general improvement of health conditions of the local populations. In the PCS design are especially considered the social and cultural contexts of the target populations, especially the customs, traditions and religion. Health Communication is considered as an Essential Function of Public Health and its main is to provide a population-based approach. The target of communication actions are population groups in addition to the individual communication, target-audiences are people without access to the media, in Guinea Bissau, Cape Verde and Sao Tome and Principe. Under the communication plan uses the methodology, models and practices both by media professionals as health. A proximity approach and cultural mediation, previously identified key facts, are defined objectives; outlines to the Plan in concrete and its implementation methodology (target-audience and following intervention, materials to be used and key-messages and partners to mobilize) following the World Health Organisation standards.

Keywords: Africa; Disease Outbreaks; Health Communication; Hemorrhagic Fever, Ebola; Information Dissemination.

\section{O problema}

A Comunicação em Saúde é uma função essencial da saúde pública que visa informar, advogar e mobilizar para ganhos em saúde. ${ }^{1}$ Entre as metodologias utilizadas [para a promoção da saúde e a prevenção da doença] considera-se a KISS \& KEYWORDS das mais eficazes - com recurso a edutainment [educação e entretenimento envolvendo o público-alvo (PA) e os diferentes meios de comunicação]. Por isso, este é um dos instrumentos do Plano de Comunicação em Saúde para evitar o contágio da doença por vírus Ébola (EVD) nos PALOP - do conhecimento/ciência à acção e da mensagem-chave à informação junto do público-alvo.
Epidemia: A região da África Ocidental está a ser alvo de uma epidemia causada por vírus Ébola afectando vários países. ${ }^{2}$ Países como Guiné-Conacri, Libéria, Serra Leoa estão a ser gravemente atingidos e têm poucos recursos para the fazer frente. Apesar das intervenções realizadas com a ajuda de diversos países e organizações, a epidemia não está controlada. ${ }^{3}$ Os países vizinhos e outros mais distantes correm o risco de serem, também, afectados.

Doença: A doença por EVD, é uma zoonose africana transmitida ao homem através de reservatório animal (morcegos da fruta) e hospedeiros intermediários (macacos e outros vertebrados). A doença provocada por EVD

\footnotetext{
1. Investigadora em Comunicação em Saúde. Instituto de Medicina Preventiva \& Saúde Pública. Faculdade de Medicina. Universidade de Lisboa. Lisboa. Portugal.

2. Assistente Convidada. Instituto de Medicina Preventiva \& Saúde Pública. Faculdade de Medicina. Universidade de Lisboa. Lisboa. Portugal.

3. Professor Catedrático de Medicina Preventiva e Saúde Pública. Instituto de Medicina Preventiva \& Saúde Pública. Faculdade de Medicina. Universidade de Lisboa. Lisboa. Portugal.

4. Diretor. Instituto de Medicina Preventiva \& Saúde Pública. Faculdade de Medicina. Universidade de Lisboa. Lisboa. Portugal

5. Especialista em Doenças Infecciosas e Medicina Tropical. Instituto de Saúde Ambiental. Faculdade de Medicina. Universidade de Lisboa. Lisboa. Portugal.

6. Professor Catedrático Emérito. Instituto de Saúde Ambiental. Faculdade de Medicina. Universidade de Lisboa. Lisboa. Portugal.

Recebido: 16 de Fevereiro de 2015 - Aceite: 27 de Abril de 2015 | Copyright $\odot$ Ordem dos Médicos 2015
} 
anteriormente incluída no grupo das febres hemorrágicas (Lassa e Marburgo), apesar da raridade das manifestações hemorrágicas, tem uma elevada taxa de letalidade em África. Os sintomas sugerem doenças comuns em África (Malária e febre Tifóide), como febre, vómitos e diarreia, acompanhados de mau estado geral e, por vezes, hemorragia. Não existe terapêutica antivírus Ébola nem vacina disponíveis.

Transmissão: O contágio só ocorre após o ínicio da doença. Durante o período de incubação [até ao $21^{\circ}$ dia] o portador não representa risco de transmissão do vírus para as pessoas que o contatam.

Intervenções: De momento, o tratamento disponível fundamenta-se nas medidas de suporte de vida, até à recuperação do doente. Para combater a epidemia, os esforços têm-se centrado na melhoria dos cuidados de saúde, na formação de pessoal técnico, nas medidas de proteção individual, no diagnóstico e tratamento precoces, muito à custa do apoio internacional. ${ }^{4} \mathrm{~A}$ informação e a educação das populações, ${ }^{5}$ principalmente dos familiares e amigos dos doentes, tem sido crucial, por forma a prevenir a transmissão, adotando medidas de proteção individual no contato com os doentes e com os cadáveres dos infetados. ${ }^{6}$ Tendo em conta o risco e expansão de novas epidemias, a informação e educação mais abrangentes, tornam-se essenciais na prevenção e no controlo de potenciais surtos epidémicos.

Países em risco: Além dos países diretamente atingidos, outros países africanos, com fronteiras terrestres comuns estão, especialmente, expostos. Os países mais distantes mas com ligações aéreas, trocas comerciais frequentes, migrações e sistemas de saúde mais débeis são também considerados vulneráveis. Por estes critérios, dos PALOP, está, particularmente, em risco, pela proximidade, a Guiné-Bissau. Mas Cabo-Verde, São Tomé e Príncipe e Angola têm também, condições, se bem que mais remotas, para a expansão da doença. Moçambique pode considerar-se menos vulnerável.

Conhecimento/ciência aos factos-chave: Até ao dia 5 de Abril de 2015, a Organização Mundial de Saúde ${ }^{7}$ registou um total de 25529 casos de EVD, relatados em 4 países (Guiné-Conacri, Libéria, Mali, Serra Leoa) e em 5 países anteriormente afetados (Estados Unidos da América, Espanha, Nigéria, Senegal). Registou-se um total de 10587 mortes. A incidência de casos notificados desceu ligeiramente na Guiné-Conacri, 21 novos casos, e na Libéria e Serra Leoa apenas um novo caso até 5 de Abril de 2015.

\section{O Plano de Comunicação em Saúde (PCS) e os Objetivos}

Plano: O PCS proposto visa contribuir para minimizar o risco de contágio por EVD nos PALOP e pretende, também, capacitar para uma melhoria geral das condições sanitárias das populações. No delineamento do PCS são, especialmente, considerados os contextos sociais e culturais das populações-alvo, com destaque para os costumes, tradições e religião. O PCS está a ser realizado em articulação com as autoridades competentes dos países visados, aos níveis nacional e local,sendo utilizadas mensagens-chave (MC) simples, acessíveis a adultos e crianças, transmitidas por diversos meios audio e visuais, através de intermediários (pontos focais) especialmente treinados para o efeito. O PCS apoia-se num edutainer (aquele a quem são atribuídas as funções de educação e entretenimento).

Objetivos: Prevenir o contágio por EVD: Comunicação e Informação em saúde junto dos habitantes das comunidades, consoante os países-alvo - através dos seus líderes e Homens-Grandes (na Guiné-Bissau), com o apoio de pontos focais (PF) ou intermediários ${ }^{8}$ especialmente treinados para o efeito pelo edutainer, incluindo as medidas de promoção da higiene.

Metodologia: Há necessidade de uma metodologia geral, isto é, da decisão sobre qual o PA, sobre as intervenções, sobre as mensagens-chave, sobre materiais, sobre a escolha de parceiros institucionais/mobilização social e advocacia para a saúde e sobre cronograma.

Metodologia Geral: Coordenação do PCS com as autoridades nacionais e locais, por forma a articular as intervenções com outros esforços em curso, diagnóstico social e cultural das populações visadas - em colaboração com os pontos focais e os líderes de forma a ajustar o PCS às realidades locais. Estabelecimento de um protocolo de comunicação, para utilização das técnicas e materiais de edutainment, adaptado a cada comunidade. Mobilização social - estabelecimento de diálogo e colaboração com os membros e grupos sociais mais relevantes, para construir a confiança coletiva e a aceitação das intervenções. Aspectos nucleares da metodologia de intervenção poderão ser sintetizados na fórmula CS: MC + PA + Prod = GS CS (Comunicação em saúde: Mensagem-Chave + Público-Alvo + Produtos $=$ Ganhos em Saúde) .

Público-alvo: Decisão e escolha dos PF - escolhidos entre os profissionais da Saúde Pública e os habitantes das comunidades (líderes de opinião e habitantes das comunidades - homens e mulheres, adultos, jovens e crianças)

Zonas Geográficas: áreas acordadas com as autoridades nacionais. Prioridades - na Guiné-Bissau são prioritárias as áreas próximas da fronteira com a Guiné-Conacri; em Cabo-Verde são prioritárias as ilhas com aeroporto internacional.

\section{A Intervenção}

Intervenção: $O$ treino dos PF nas várias etapas de intervenção, em particular, nas ações de edutainment é o ponto de partida para o PCS. São essenciais as reuniões com os líderes das comunidades para explicação de todo o processo e familiarização com o programa de trabalhos e conteúdos. As sessões de edutainment com os habitantes - separadas para homens e mulheres, ou tomando em consideração os grupos sociais, conforme os hábitos e tradição das comunidades - são o ponto de partida para a ação no terreno, assim como as ações envolvendo os media disponíveis (utilizando os dialetos), os SMS para telemóveis, filmes (reportagens) e ações de edutainment 
nas TV locais, spots nas rádios locais, folhetos e cartazes com MC. No que se refere às mensagens-chave, KISS \& KEYWORDS (KISS: Keep It Short and Simple - Keywords - Palavras curtas e simples e Palavras chave em mensagens-chave) - relativas aos riscos de transmissão do vírus e sua prevenção, nomeadamente sobre a higiene nos funerais, a higiene pessoal (mãos, excreta) e a higiene das mães para com as crianças.

Materiais: Os materiais a utilizar são: 1. Cartazes [plastificados] evocando a prevenção da Doença por vírus Ébola, com quatro figuras ilustrativas (Fig. 1) das Mensagens-Chave, sendo oferecidos e afixados [depois de descodificados] em cada comunidade [este material foi preparado em parceria com o Departamento de Desenho da Escola Secundária e Artística portuguesa - António Arroio - e o Instituto de Medicina Preventiva \& Saúde Pública]; 2. Traje para o comunicador em saúde/Ponto Focal ou Mediador Cultural - de modo a ser facilmente reconhecido e se inserir no seio da comunidade; 3 . Desenhos e ilustrações para apoio das sessões e media - explicativos das Mensagens-Chave, a desenvolver por cada líder e elementos das comunidades em ações de edutainment; 4. Peças de rádio, televisão e SMS.

\section{AGRADECIMENTOS}

Leonor Bacelar Nicolau Investigadora em Economia da Saúde e Assistente no Instituto de Medicina Preventiva \& Saúde Pública, Faculdade de Medicina da Universidade de Lisboa, Escola Secundária e Artística António Arroio, Ministério da Saúde de Portugal. Ministério da Saúde Pública de Guiné Bissau, Ministério da Saúde de São Tomé e Príncipe, Ministério da Saúde de Cabo Verde e Fundação Luso Americana para o Desenvolvimento. Parceiros institucionais: Instituições proponentes - IMP\&SP, FMUL com apoio do Ministério da Saúde (MS) de Portugal. Instituições beneficiárias - Ministério da Saúde da Guiné-Bissau, Ministério da Saúde de Cabo Verde, Ministério da Saúde de São Tomé e Príncipe. Equipa: Unidade de Comunicação em Saúde do IMP\&SP,FMUL (edutainer \& comunicador em saúde). Orientação Científica: José Pereira Miguel e Francisco Antunes. O projeto decorre de Janeiro a Junho de 2015. Avaliação: O processo e os resultados do Plano de Comunicação em Saúde serão submetidos à avaliação, do ensino e das sessões, pelos Pontos Focais e Intermediários e pelos habitantes, da aprendizagem, pela equipa de projeto e global pelas instituições de saúde dos países beneficiários.
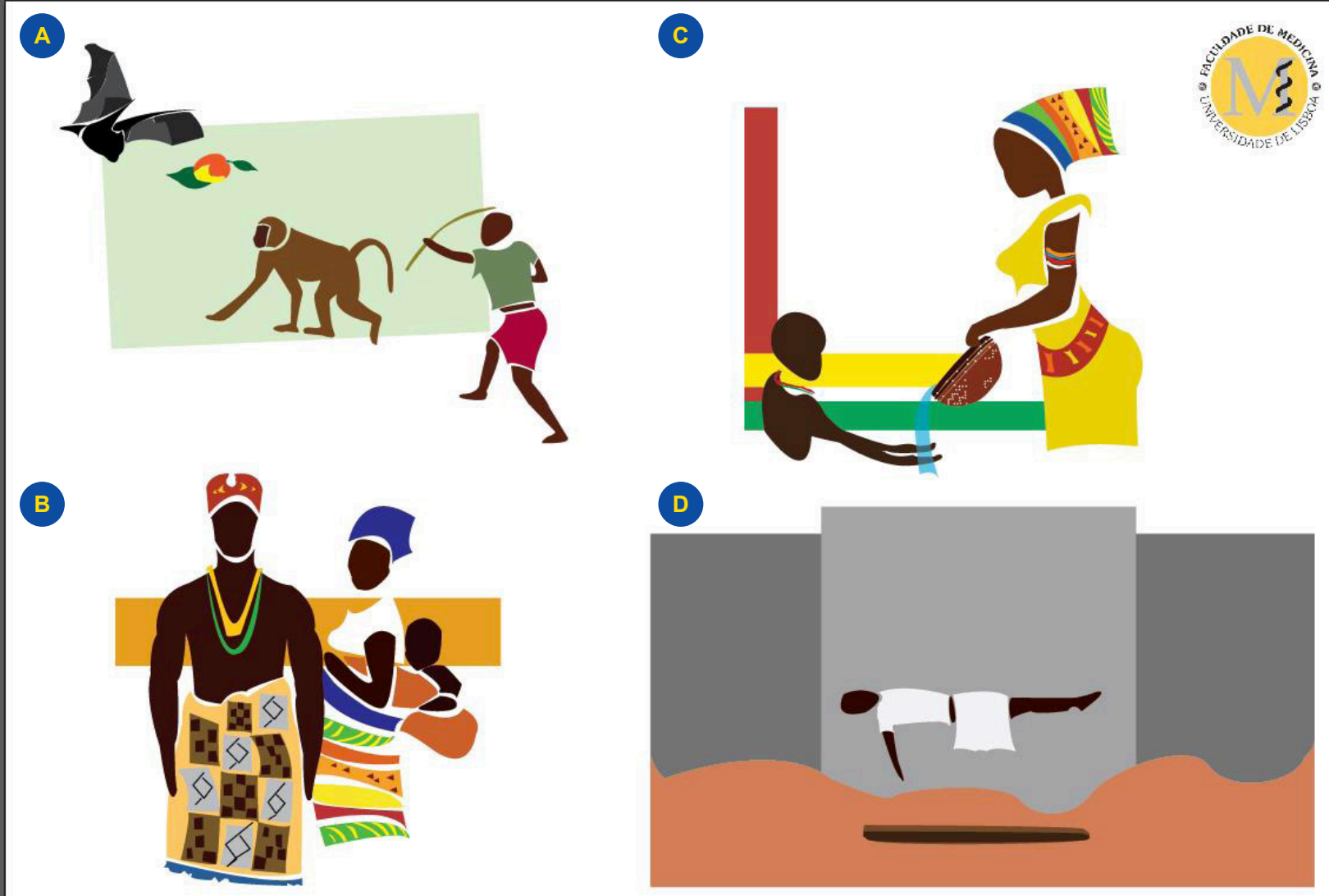

Figura 1 - Figuras ilustrativas das mensagens-chave utilizadas nos materiais para oferecer e afixar no decurso das campanhas de Plano de Comunicação em Saúde. A, B, C e D, respetivamente o reservatório animal e a relação homem/caça de vertebrados; o Homem-Grande ou líder de comunidade como responsável da estratégia de comunicação em saúde a seguir, após o treino; a relação mãe-filho ou cuidador-criança na comunidade e os cuidados de higiene e a morte - como meios necessários para a suspensão de tradições e costumes no período da epidemia], sendo oferecidos e afixados [depois de descodificados] Autor: Ana Rita Simões (sob orientação da Unidade de Comunicação em Saúde do Instituto de Medicina Preventiva \& Saúde Pública - Faculdade de Medicina da Universidade de Lisboa), Curso de Design de Comunicação especialização de Design Gráfico, Escola Secundária e Artística António Arroio - inseridos em projeto Fundação para a Ciência e Tecnologia. 


\section{CONFLITOS DE INTERESSE}

Os autores declaram não ter quaisquer conflitos de interesse relativamente ao presente artigo.

\section{REFERÊNCIAS}

1. World Health Organization [homepage na internet]. Global Ebola Response Monitoring and Mapping System [Consultado 2015 Jan 26]. Disponivel em: http://maps.who.int/MapGallery/.

2. Aylward B, Barboza P, Bawo L, Bertherat E, Bilivogui P, Blake I, et al. Ebola virus disease in west Africa - the first 9 months of the epidemic and forward projections. N Engl J Med. 2014; 371:1481-95.

3. Ebola: what lessons for the IHR. Lancet 2014;384:1321.

4. Martin-Moreno JM, Ricciardi W, Bjegovic-Mikanovic V, Maguire $P$, McKee M. Ebola: an open letter to European governments. The Lancet. 2014;384:1259.

5. Marshall, Patricia A. Ethical challenges in study design and informed consent for health research in resource-poor settings [e-book]

\section{FONTES DE FINANCIAMENTO}

Fundação Luso-Americana.

[Consultado em 2015 Jan 26]. Disponível em: http://whqlibdoc.who.int/ publications/2007/9789241563383_eng.pdf.

6. Cash R, W Daniel, Saxena A, Capron A, editors. Casebook on Ethical Issues in International Health Research. Geneva: World Health Organization: 2009 [Consultado 2015 Jan 26], p 16. Disponível em: http://whqlibdoc.who.int/publications/2009/9789241547727_eng. pdf?ua=1.

7. World Health Organization [homepage na internet]. Global Ebola Response Monitoring and Mapping System [Consultado 2015 Jan 26]. Disponível em: http://maps.who.int/MapGallery/.

8. Dhillon SR, Srikrishna D, Sachs J. Ebola, controlling Ebola: next steps. Lancet. 2014:384:1409-11. 
Isabel DE SANTIAGO, José Pereira MIGUEL, Francisco ANTUNES

\section{Comunicação em Saúde: Evitar o Contágio da Doença por Vírus Ébola nos PALOP _ Metodologia KISS \& KEYWORDS}

Acta Med Port 2015:28:141-144

Publicado pela Acta Médica Portuguesa, a Revista Científica da Ordem dos Médicos

Av. Almirante Gago Coutinho, 151

1749-084 Lisboa, Portugal.

Tel: +351218428 215

E-mail: submissao@actamedicaportuguesa.com

www.actamedicaportuguesa.com

ISSN:0870-399X | e-ISSN: 1646-0758

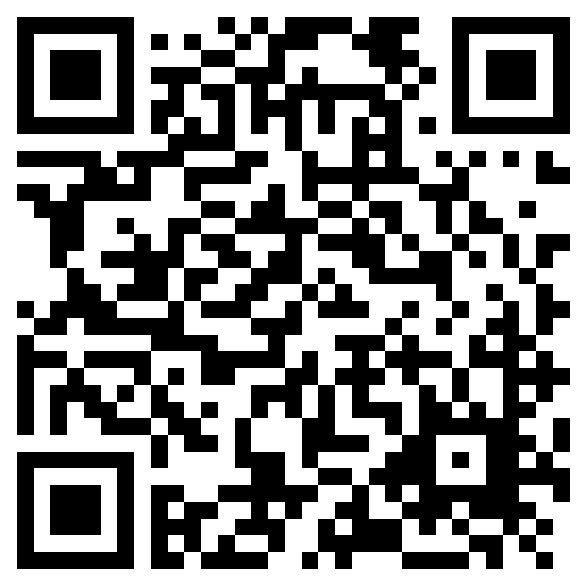

